\title{
Access Differentials in Primary Healthcare among Vulnerable Populations in a Health Insurance Setting in Kumasi Metropolis, Ghana: A Cross-Sectional Study
}

\author{
Gertrude Acquah-Hagan $\mathbb{D}^{\mathbb{D}},{ }^{1,2}$ Daniel Boateng $\mathbb{D}^{\mathbb{D}},{ }^{1}$ Emmanuel Appiah-Brempong, ${ }^{1}$ \\ Peter Twum (D), ${ }^{1}$ Joseph Amankwa Atta, ${ }^{3}$ and Peter Agyei-Baffour ${ }^{1}$ \\ ${ }^{1}$ School of Public Health, Kwame Nkrumah University of Science and Technology, Kumasi, Ghana \\ ${ }^{2}$ Suntreso Government Hospital, Kumasi, Ghana \\ ${ }^{3}$ Methodist Hospital, Ankaase, Ashanti, Ghana
}

Correspondence should be addressed to Gertrude Acquah-Hagan; gertrudeah71@yahoo.co.uk

Received 1 April 2021; Accepted 13 July 2021; Published 27 July 2021

Academic Editor: Carol J. Burns

Copyright (c) 2021 Gertrude Acquah-Hagan et al. This is an open access article distributed under the Creative Commons Attribution License, which permits unrestricted use, distribution, and reproduction in any medium, provided the original work is properly cited.

\begin{abstract}
Background. Access to healthcare remains a challenge towards the achievement of the Sustainable Development Goals in Ghana. There still remain inequalities in the distribution of health services especially among vulnerable groups despite sustained efforts to strengthen the health system. This study was conducted to analyze access differentials among different vulnerable groups in the context of primary healthcare under a National Health Insurance Scheme (NHIS) in Ghana. Methods. This study was a descriptive cross-sectional study conducted among multilevel participants of vulnerable groups in Kumasi Metropolis: 710 vulnerable people constituting elderly/aged $(n=359)$, pregnant women $(n=117)$, head poters (teenage girls who migrated from the northern Ghana mainly to the capital cities of the Ashanti and Greater Accra region to help in carrying of goods for their livelihood) $(n=86)$, sex workers $(n=75)$, and other vulnerable groups (people with disabilities and street participants) $(n=73)$. Data were collected using a semistructured questionnaire. Poisson regression with robust variance was used to access the association between vulnerability and access to healthcare. Results. Close to a fifth, $18.5 \%$ of the study respondents were unable to access care at any point in time during the last 12 months. Reasons for the inability to access healthcare included limited funding $(69.7 \%)$, poor attitude of service providers $(7.6 \%)$, distance to health centers $(8.3 \%)$, and religious reasons $(6.2 \%)$. More than $95 \%$ of respondents were insured under the NHIS, but acceptability of service provision under the NHIS was low among the vulnerable groups. In the crude models, pregnant women had lower prevalence of access to medications as compared to the elderly (prevalence ratio (PR): 0.88 ; $95 \% \mathrm{CI}$ : $0.80-0.98$ ). Head poters and other vulnerable groups were also less likely to view healthcare as affordable as compared to the elderly. The differences in healthcare access observed were attenuated after adjustment for sociodemographic characteristics and healthcare-related factors. Conclusions. Despite the introduction of a NHIS in Ghana, this study highlights challenges in healthcare access among vulnerable populations independent of the type of vulnerability. This suggests the need for stakeholders to work to address access differentials in the NHIS and adopt other innovative care strategies that may have broader applicability for all populations.
\end{abstract}

\section{Introduction}

Access to healthcare remains a challenge towards the achievement of the Sustainable Development Goals (SDGs) in many low- and middle-income countries (LMICs) including Africa [1]. Interventions aimed at improving access to quality care especially among the vulnerable populations in LMICs are top priorities of stakeholders of SDGs. Smoothening the progress of access to healthcare involves helping people to command appropriate healthcare 
resources and to seek care in order to preserve or improve their health. It is worth noting that access is a complex concept. However, four aspects require empirical evaluation. These are availability, affordability, physical accessibility, and acceptability $[2,3]$. Equity in access may be measured in terms of the availability, utilization, or outcomes of services. If services are available and there is an adequate supply of services, then the opportunity to obtain healthcare exists, and a population may "have access" to services. Most often, this depends on economic, organizational, and sociocultural barriers that limit the utilization of health services. Thus, access measured in terms of utilization is dependent on the affordability, physical accessibility, and acceptability of services and not merely adequacy of supply [4].

Despite sustained efforts to strengthen the healthcare system and significant progress, there exist critical shortages of health professionals and inequalities in the distribution of health services especially among vulnerable groups in Africa [5]. The African region is home to many vulnerable populations, many of whom experience numerous barriers to accessing healthcare [6-9]. According to a report from the African Health Agenda International Conference (AHAIC) Commission report, health systems in Africa are failing to meet the needs of the poor, the marginalized, and the disabled, due to challenges ranging from discrimination and stigma to poorly designed healthcare facilities [9].

Vulnerable populations often live in isolated communities which cause difficulty travelling to the desired healthcare service location due to transport costs or lack of transport links and missing appointments due to transport delays [10]. Structural barriers and poorer health infrastructure within health systems need to be improved to ensure health equality for those vulnerable to poverty and social exclusion [11]. These structural barriers cause significant problems with healthcare delivery. Healthcare to vulnerable groups is conceptualized as a multidimensional construct consisting of pragmatics, health knowledge and beliefs, expectations about care, skills, and marginalization $[12,13]$.

In Ghana, there is little information about the rate of utilization among various vulnerable groups such as sex workers, people with disabilities, drug users, street children aged 18 years and above, female poters, prisoners, pregnant women, elderly women, and orphans. Nevertheless, this information is essential as it will help policymakers to know the rate of access to healthcare services among the most marginalized population in the Ghanaian society and respond accordingly. Understanding the factors that influence differences in healthcare access and utilization within vulnerable groups in Ghana can also serve as a basis for accurate projection of future healthcare needs. This study therefore aims at assessing the healthcare access differentials among the vulnerable populations in a capitation health insurance setting and makes this information available to inform policy.

This paper seeks to answer, "Does the National Health Insurance Scheme (NHIS) in Ghana improve access to quality healthcare among the vulnerable and to what extent?" and analyzes the access differentials among different vulnerable groups in the context of primary healthcare within the Kumasi Metropolis of Ghana. Research shows that coverage of intervention that deems to be effective at a low cost is below $50 \%$ due to the inability to reach the most vulnerable and population in need [14]. Mills et al. [15] found in Ghana, Tanzania, and South Africa that the most vulnerable population such as the poor have the least involvement in the health insurance programmes. The distribution of insurance services favours the rich in these countries more than the lower income population. Inadequate arrangement mechanisms to cover access to healthcare for the vulnerable in the Ghanaian society have the implication of drawback in the country.

1.1. Vulnerability and Access to Healthcare under the National Health Insurance Scheme. The role of health insurance towards Universal Health Coverage (UHC) has in some cases increased inequity of access to healthcare services [16]. As a consequence of the deleterious effects of user fees on healthcare accessibility, one of the primary goals of Ghana's NHIS was to increase access to primary healthcare. Ghana's health insurance is financed through a central National Health Insurance Fund (NHIF) sourced from the National Health Insurance Levy (NHIL) of $2.5 \%$ tax on selected goods and services; $2.5 \%$ of Social Security and National Insurance Trust (SSNIT) contributions, largely by formal sector workers; and payment of premiums and donor funds. Overall, more than $60 \%$ of active members of the NHIS are under the premium exemption category (i.e., people under 18 years or $70+$ years, pregnant women, and indigents) [17].

Under the NHIS, healthcare has been extended towards the poor and most vulnerable populations in particular [18]. According to Witter and Garshong, the operationalization of NHIS led to an increase in health access in Ghana [19]. Access to healthcare among vulnerable populations has however not been investigated. The NHIS is a pro-poor programme focused on targeting the poor for exemption. As a result of challenges in targeting and correctly identifying the poor, the NHIS has not been able to provide equitable coverage of the poor.

1.2. Conceptual Module. The conceptual foundation for this study was based on the access framework proposed by Levesque, Harris, and Russel [20]. The framework builds on previous conceptualizations of access [21, 22] and is in continuous development with proposals which take into account social and health dimensions of access within an equity perspective [23]. The authors merge both dimensions of supply and demand into the access framework by building on a comprehensive view of access expressed around individual factors, healthcare-related factors, and the broad context. This allows access to be operationalized along the line of healthcare utilization from the perception of need through to service outcomes.

The framework is made up of five dimensions of accessibility of healthcare and five corresponding abilities of patients and populations to access healthcare. These dimensions are arranged in pairs, with each access and 
demand-side abilities mirroring each other. The dimensions of accessibility are approachability, acceptability, availability and accommodation, affordability, and appropriateness, and the corresponding abilities of patients and populations to access healthcare were ability to perceive, ability to seek, ability to reach, ability to pay, and ability to engage as shown in Supplementary Figure 1. These dimensions of access are however considered to be interdependent constructs. Supplementary Table 1 describes the operational definitions of each access dimension.

\section{Method}

2.1. Study Design and Setting. This was a descriptive crosssectional study conducted in the Kumasi Metropolis of Ghana. This study site selection is based on its cosmopolitan nature, which makes it likely to have various vulnerable groups with diverse socioeconomic backgrounds. Approximately two-thirds of the Ashanti region population live in Kumasi Metropolis, making it a rapidly growing urban city. The metropolis accommodates a resident population of $2,035,064$ as in 2010 with an average annual growth rate of 2.6\% [24]. The metropolis is divided into 10 submetropolitan districts Asewase, Asokwa, Bantama, Manhyia, Oforikrom, Tafo, Nhyiaeso, Subin, Suame, and Kwadaso. It is also endowed with 189 health facilities ranging from teaching hospitals, clinics, and maternity homes. About 150 of the health facilities representing $91 \%$ are managed by private individuals.

2.2. Study Population. The target population for this study was multilevel participants from vulnerable groups in Kumasi Metropolis. Participants were selected based on certain characteristics that account for individual or multiple risk factors to healthcare access. Individuals of age 18 years and above who were identified as vulnerable by the vulnerability profile were enrolled into the study. The target group was characterized by sex workers, people with disabilities, street participants aged 18 years and above, female poters, pregnant women, elderly women, and orphans.

2.3. Sampling and Sample Size. The sample size was calculated by considering the proportion of the population in Kumasi Metropolis who are considered as vulnerable groups to participate in this study. This study assumed $50 \%$ of the vulnerable groups to calculate the sample size since there were no formal data on the proportion of vulnerable groups in the metropolis. On the basis of access, the proportion of vulnerable population having access to healthcare was compared between the study groups. The sample size calculation assumes that an access preference rate of $65 \%\left(P_{1}\right)$ among the vulnerable population is required for improved healthcare access. With a null hypothesis of no access differentials among the vulnerable groups, it is further assumed that the proportion of vulnerable population accessing healthcare is $50 \%\left(P_{2}\right)$. With a $95 \%$ confidence interval, a significance level of 0.05 , and a power of $80 \%$, the sample size (n) was calculated based on two proportion formula by Kirkwood and Sterne [25] as follows:

$$
n=\left[u \sqrt{P_{1}}\left(1-P_{1}\right)+P_{2}\left(1-P_{1}\right)+v \sqrt{\left(P_{1}+P_{2}\right)}\left(1-\frac{P_{1}+P_{2}}{2}\right)^{2}\right]
$$

$$
\left(P_{1}-P_{2}\right)^{2}=170 \text {. }
$$

Including a design effect of 1.2 and a nonresponse rate of $15 \%$, a sample size of 235 participants per vulnerable group was estimated to be included. The final sample included 359 elderly/aged, 117 pregnant women, 86 head poters, 75 sex workers, and 73 other vulnerable groups (people with disabilities and street participants). Head poters are teenage girls who migrated from districts and constituencies in the northern part of Ghana, i.e., the Northern Region, Savannah Region, North-East Region, Upper East, and Upper West to the capital cities of the Ashanti and Greater Accra region to help in carrying of goods for their livelihood. Majority of these girls sleep in the market and lorry stations after their daily hustle and are exposed to sexual harassments which in many instances results in teenage pregnancies.

This study employed different approaches to sample participants. The study used cluster sampling to select individual households who are stratified by vulnerability. The study divided Kumasi Metropolis into vulnerability enclaves. Using vulnerability enclaves, the study first selected clusters of communities identified as busy with and/or occupied by vulnerable groups. In such communities, both simple random and snowballing sampling techniques were used to enroll vulnerable people into the study.

2.4. Data Collection. Data for this study were collected using a semistructured questionnaire. The questionnaires included open-ended and closed questions based on the objectives of the study. The study again had separate questions on the sociodemographic information such as age, gender, marital status, religion, occupation, income level, education level, assets owned by participants, and type of residency using a sociodemographic form. Questionnaire and data collected were checked for consistency and protected under lock and key. For reliability and validity of the study conclusions, a 3day training session was held for the research assistants by the principal investigator. The data collection tools were pretested on 50 households prior to data collection. data collection, the study was explained to respondents and consent was duly sought.

2.5. Data Analysis. The background information of respondents was assessed and categorized into socioeconomic status using income, assets index, or other available data. Data were first presented as frequency tables or charts to assess the distribution. This was followed by bivariate analysis where selected study variables were related to the various outcomes of interest from the study objectives. The final stage of the analysis explored the strength of study independent variables in influencing the outcomes of 
interest, where necessary relevant variables were controlled for in assessing their influence or impact on the outcome of interest. The bivariate analysis involved the use of Pearson chi-square to aess differences in access, utilization, service availability, and affordability among various vulnerable groups (elderly, pregnant women, head poters, sex workers, and other groups). $P$ values for associations were reported to indicate the significance of these differences. The multivariable analyses involved the use of Poisson regression with robust variance to estimate prevalence ratios and corresponding 95\% confidence intervals (CIs) and $P$ values. Poisson regression with robust variance, which is a generalized linear model (GLM), was chosen because the outcomes are binary (present or absent) and the prevalence was not rare (>10\%) [26]. In this instance, the Poisson regression is found to offer a more precise estimate than the logistic regression, which tends to overestimate the effect sizes [26].

The dependent variable was access and utilization of healthcare services, defined as access to medications within the past twelve months. The independent variable was the type of vulnerable group (elderly, pregnant women, sex workers, head poters, and others). Two models were fitted. Model 1 adjusted for the sociodemographic characteristics (gender, age, level of education, employment, marital status, number of children, religion, and wealth status) of the study participants while model 2 involved adjustment for the sociodemographic characteristics together with healthcarerelated factors (NHIS subscription, exemption from health cost, and relationship with health staff). The description of the study variables is shown in Supplementary Table 2.

2.6. Ethical Considerations. In a study that utilizes human participants such as vulnerable groups who are tagged as marginalized, it is necessary to consider issues of confidentiality and privacy. Assurance of strict privacy will motivate prospective study participants. Among the significant issues included informed consent, confidentiality, and data protection. The Committee for Human Research Publication and Ethics at Kwame Nkrumah University of Science and Technology (KNUST)/Komfo Anokye Teaching Hospital (KATH) reviewed and cleared the study protocols prior to the implementation of the methods. A written informed consent was explained to participants who consented to the study prior to their enrolment.

\section{Results}

3.1. Background Characteristics of Respondents. Almost three-fourth $(74.6 \%)$ of the respondents were female, and the mean (SD) age of the participants was 51 (21.0) years. About $36 \%$ of the participants had no formal education, whereas $35.7 \%$ had basic (primary and junior secondary school) education. Only $3 \%$ had tertiary education. Majority (65\%) were employed and $21.9 \%$ and $35.2 \%$ were artisans and traders, respectively. About $12 \%$ and $12.6 \%$ were prostitutes and head poters, respectively. About $41 \%$ were married whereas $15.7 \%$ were single with $24.2 \%$ being widowed. Almost half of the participants had more than three children. Most of the study participants rated themselves as moderately rich, whereas $31.3 \%$ rated themselves poor. About $22 \%$ and $18.4 \%$ belonged to the lowest and highest wealth quintiles, respectively (Table 1 ).

\subsection{Access and Utilization of Healthcare Services by Vulner-} able Groups. Table 2 shows the results of accessibility and utilization of primary healthcare among different vulnerable groups. About $80 \%$ of the respondents had fallen sick in the last 12 months and $18.5 \%$ disclosed that they were unable to access care at any point in time during the last 12 months. Reasons for the inability to access healthcare included limited funding (69.7\%), poor attitude of service providers $(7.6 \%)$, distance to health centers, $(8.3 \%)$, and religious reasons $(6.2 \%)$ as shown in Figure 1. The proportion of respondents who were unable to access care at any point in the previous 12 months differed significantly between the vulnerable groups, with access being higher among sex workers and lower among the elderly $(P=0.001)$. The proportion of respondents who had taken more than 3 treatment actions in the previous 12 months was higher among the elderly and lowest among pregnant women. The hospital was the most preferred source of healthcare among all groups except for sex workers, where $46.7 \%$ and $37.4 \%$ preferred the hospital and the clinic, respectively. Reasons for choice were proximity (51\%), high-quality staff (40.7\%), affordability (14.9\%), and recommended by someone (12.4\%). Most respondents from all vulnerable groups visited their preferred source of healthcare regularly, except for sex workers who mostly (72.2\%) visited their preferred source of care only when they are sick. The means of transport to source of care also differed significantly among the vulnerable groups $(P<0.001)$.

The perception of the NHIS among the various vulnerable groups is presented in Table 3. The mean (SD) responses indicated that the majority of respondents believed that the NHIS was not enough to provide their healthcare needs, with mean response being higher among sex workers and lowest among female head poters. Mean responses on long waiting time at the facility, expensiveness of the NHIS premium, and feeling of discrimination under the NHIS were also significantly higher among sex workers.

The proportion of respondents covered by the health insurance and having their policy currently active differed significantly among the vulnerable groups (Table 4). The proportion of respondents who had ever been exempted were significantly higher among the female porters $(61.0 \%)$ and pregnant women $(59.8 \%)$ and lower among the sex workers (26\%). The sources of payment for the NHIS also differed among the vulnerable groups, with most of the sex workers and elderly paying for NHIS themselves and most of the pregnant women, head porters, and other valuable groups exempted from paying for the NHIS. The proportion of respondents who paid for services even with their NHIS card and encountered any problem with the NHIS were also significantly different among the vulnerable groups. The elderly were more likely to aess a public facility with their 
TABLE 1: Background characteristics of vulnerable groups.

\begin{tabular}{|c|c|c|}
\hline Background characteristics & Frequency $(n=710)$ & Percentage \\
\hline \multicolumn{3}{|l|}{ Gender } \\
\hline Male & 180 & 25.4 \\
\hline Female & 530 & 74.6 \\
\hline Age (mean, SD) & $51,21.0$ & \\
\hline \multicolumn{3}{|l|}{ Age groups } \\
\hline$\leq 18$ & 22 & 3.1 \\
\hline $19-30$ & 196 & 27.6 \\
\hline $31-50$ & 91 & 12.8 \\
\hline $51-64$ & 165 & 23.2 \\
\hline$\geq 65$ & 236 & 33.2 \\
\hline \multicolumn{3}{|l|}{ Level of education } \\
\hline None & 252 & 35.5 \\
\hline Basic education (primary and JSS) & 254 & 35.7 \\
\hline Professional certificate & 17 & 2.4 \\
\hline Senior high school/middle school & 166 & 23.4 \\
\hline Tertiary & 21 & 3.0 \\
\hline \multicolumn{3}{|l|}{ Employment $(n=674)$} \\
\hline Employed & 438 & 65.0 \\
\hline Unemployed & 236 & 35.0 \\
\hline \multicolumn{3}{|l|}{ Type of employment $(n=438)$} \\
\hline Civil/servant & 18 & 4.1 \\
\hline Artisan & 96 & 21.9 \\
\hline Trader & 154 & 35.2 \\
\hline Farmer & 20 & 4.6 \\
\hline Prostitution & 53 & 12.1 \\
\hline Self-employed & 42 & 9.6 \\
\hline Head potter & 55 & 12.6 \\
\hline \multicolumn{3}{|l|}{ Marital status $(n=657)$} \\
\hline Single & 103 & 15.7 \\
\hline Cohabitation & 81 & 12.3 \\
\hline Married & 272 & 41.4 \\
\hline Divorced & 29 & 4.1 \\
\hline Widowed & 172 & 24.2 \\
\hline \multicolumn{3}{|l|}{ Number of children $(n=587)$} \\
\hline 0 & 23 & 3.9 \\
\hline 1 & 94 & 16.0 \\
\hline 2 & 111 & 18.9 \\
\hline 3 & 64 & 10.9 \\
\hline$>3$ & 295 & 50.3 \\
\hline \multicolumn{3}{|l|}{ Number of dependents $(n=453)$} \\
\hline 0 & 16 & 3.5 \\
\hline 1 & 65 & 14.3 \\
\hline 2 & 175 & 38.6 \\
\hline 3 & 47 & 10.4 \\
\hline$>3$ & 150 & 33.1 \\
\hline \multicolumn{3}{|l|}{ Ethnic group $(n=666)$} \\
\hline Akan & 457 & 68.6 \\
\hline Ewe & 30 & 4.5 \\
\hline Northerner & 111 & 16.7 \\
\hline Other & 68 & 10.2 \\
\hline \multicolumn{3}{|l|}{ Religion $(n=671)$} \\
\hline Christian & 573 & 85.4 \\
\hline Muslim & 90 & 13.4 \\
\hline Others & 10 & 14.9 \\
\hline Average monthly income in GHC (mean, SD) & $399.04(383.53)$ & \\
\hline Have other sources of income & 114 & 16.1 \\
\hline \multicolumn{3}{|l|}{ Place of residence $(n=653)$} \\
\hline Zongo & 52 & 8.0 \\
\hline
\end{tabular}


TABle 1: Continued.

\begin{tabular}{lcc}
\hline Background characteristics & Frequency $(n=710)$ & Percentage \\
\hline Slum & 86 & 13.2 \\
Old town & 285 & 43.6 \\
New site & 178 & 27.3 \\
Estate & 38 & 5.8 \\
Others & 14 & 2.1 \\
\hline Rate of socioeconomic status $(n=656)$ & & 2.0 \\
Very rich & 13 & 4.9 \\
Rich & 32 & 55.8 \\
Moderately rich & 366 \\
Poor & 205 \\
Very poor & 40 \\
\hline Wealth quintiles & & 31.3 \\
Lowest & 145 \\
Mew & 115 \\
High & 144 \\
Highest & 125 \\
\hline
\end{tabular}

TABLE 2: Accessibility and utilization of primary healthcare among vulnerable groups.

\begin{tabular}{|c|c|c|c|c|c|c|c|}
\hline \multirow[b]{2}{*}{$\begin{array}{l}\text { Accessibility and utilization of primary } \\
\text { health }\end{array}$} & \multirow[b]{2}{*}{$\begin{array}{l}\text { Total } \\
(\%)\end{array}$} & \multicolumn{5}{|c|}{ Vulnerable groups } & \multirow[b]{2}{*}{$\begin{array}{c}P \\
\text { value }\end{array}$} \\
\hline & & $\begin{array}{l}\text { Elderly } \\
\quad(\%)\end{array}$ & $\begin{array}{c}\text { Pregnant } \\
\text { women }(\%)\end{array}$ & $\begin{array}{c}\text { Female } \\
\text { porters }(\%)\end{array}$ & $\begin{array}{l}\text { Sex workers } \\
(\%)\end{array}$ & $\begin{array}{l}\text { Others* } \\
\text { (\%) }\end{array}$ & \\
\hline $\begin{array}{l}\text { Unable to access care at any point in time } \\
\text { during last } 12 \text { months }\end{array}$ & 18.5 & 15.3 & 22.4 & 27.1 & 35.2 & 16.7 & 0.001 \\
\hline \multicolumn{8}{|l|}{ Treatment actions taken last 12 months } \\
\hline 1 & 18.8 & 4.6 & 43.2 & 23.3 & 41.9 & 19.4 & \multirow{4}{*}{$<0.001$} \\
\hline 2 & 33.0 & 27.9 & 36.4 & 51.7 & 27.4 & 61.3 & \\
\hline 3 & 17.5 & 21.5 & 13.6 & 11.7 & 19.4 & 0.0 & \\
\hline$\geq 4$ & 31.6 & 46.0 & 6.8 & 13.4 & 11.3 & 19.4 & \\
\hline \multicolumn{8}{|l|}{ Type of healthcare visits } \\
\hline Ambulatory visits & 90.9 & 93.7 & 85.6 & 94.3 & 63.8 & 97.8 & \multirow{3}{*}{$<0.00$} \\
\hline Emergency department & 2.6 & 0.9 & 4.8 & 1.4 & 12.1 & 0.0 & \\
\hline Hospitalized & 6.5 & 5.5 & 9.6 & 4.3 & 24.1 & 2.2 & \\
\hline \multicolumn{8}{|l|}{ Most preferred sources of healthcare } \\
\hline Clinic & 7.5 & 7.5 & 5.0 & 3.7 & 37.4 & 5.7 & \multirow{7}{*}{$<0.001$} \\
\hline Health center & 1.0 & 0 & 1.5 & 0.0 & 4.0 & 0.0 & \\
\hline Private physician office & 4.4 & 0 & 9.5 & 11.7 & 2.7 & 9.4 & \\
\hline Spiritual healing center & 2.8 & 0 & 1.5 & 0.0 & 0.0 & 0.0 & \\
\hline Hospital & 77.6 & 90.3 & 73.0 & 61.5 & 46.7 & 73.6 & \\
\hline Self-medication & 7.0 & 1.4 & 9.5 & 22.1 & 9.3 & 11.3 & \\
\hline Others; herbal medicines & 1.1 & 0.8 & 0.0 & 0.0 & 0.00 & 0.0 & \\
\hline \multicolumn{8}{|c|}{ How often do you visit your preferred sources? } \\
\hline Only when am sick & 31.0 & 24.4 & 30.1 & 34.1 & 72.2 & 16.0 & \multirow{3}{*}{$<0.001$} \\
\hline Regularly & 60.3 & 71.4 & 58.6 & 55.3 & 16.7 & 58.0 & \\
\hline Occasional & 8.7 & 4.2 & 11.3 & 10.6 & 11.1 & 28.0 & \\
\hline \multicolumn{8}{|c|}{ Have you been prescribed to take any medication? } \\
\hline Yes & 91.0 & 85.1 & 99.2 & 96.5 & 93.2 & 100.0 & \multirow{2}{*}{$<0.001$} \\
\hline No & 9.0 & 14.9 & 0.8 & 3.5 & 6.8 & 0.0 & \\
\hline \multicolumn{7}{|l|}{ Means of transport to source of care } & $<0.001$ \\
\hline Car & 81.3 & 84.4 & 88.3 & 73.3 & 76.0 & 69.9 & \multirow{4}{*}{$<0.001$} \\
\hline Bicycle & 0.9 & 0.0 & 0.0 & 2.3 & 0.0 & 7.5 & \\
\hline On foot & 17.4 & 14.8 & 11.7 & 24.4 & 24.0 & 22.6 & \\
\hline Others & 0.4 & 0.8 & 0.0 & 0.0 & 0.0 & 0.0 & \\
\hline
\end{tabular}

* People with disabilities, drug users, prisoners, and orphans. 


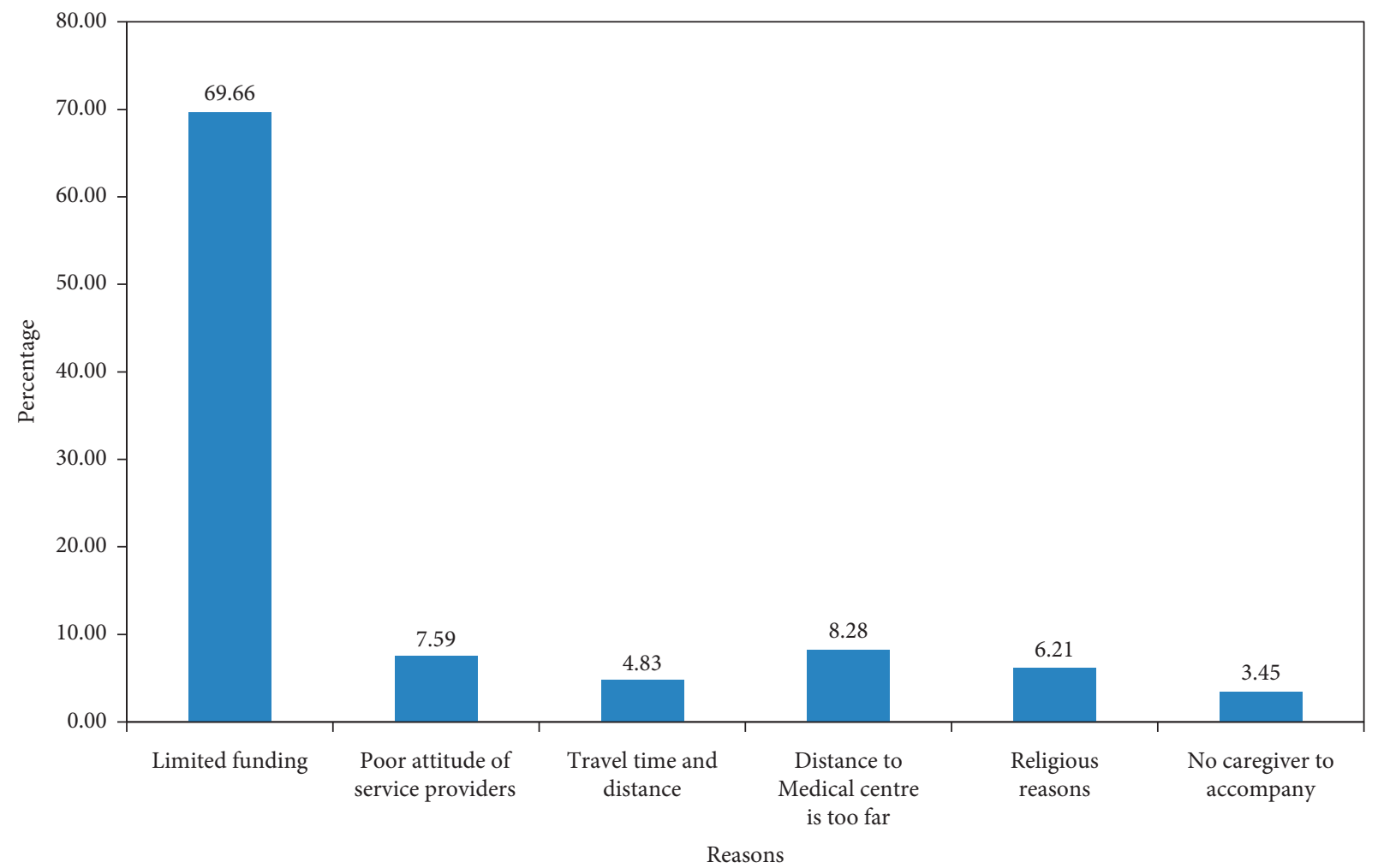

Figure 1: Reasons for the inability to access care.

TABLE 3: Perception of the NHIS by vulnerable groups.

\begin{tabular}{|c|c|c|c|c|c|c|}
\hline \multirow[b]{2}{*}{ Variables } & \multicolumn{5}{|c|}{ Groups } & \multirow[b]{2}{*}{$\begin{array}{c}P \\
\text { value }\end{array}$} \\
\hline & $\begin{array}{c}\text { Elderly } \# \\
\text { Mean } \\
\text { (SD) }\end{array}$ & $\begin{array}{l}\text { Pregnant } \\
\text { women } \\
\text { Mean (SD) }\end{array}$ & $\begin{array}{c}\text { Female } \\
\text { porters } \\
\text { Mean }(S D)\end{array}$ & $\begin{array}{c}\text { Sex } \\
\text { workers } \\
\text { Mean } \\
(\mathrm{SD})\end{array}$ & $\begin{array}{c}\text { Others* } \\
\text { Mean } \\
\text { (SD) }\end{array}$ & \\
\hline NHIS is not enough to provide my healthcare needs & $4.5(1.8)$ & $4.5(1.7)$ & $3.9(1.7)$ & $4.9(2.1)$ & $4.1(1.7)$ & 0.017 \\
\hline NHIS does not cover all medical and other equipment expenses & $5.0(1.6)$ & $4.5(1.7)$ & $4.2(1.4)$ & $5.6(1.7)$ & $4.5(1.3)$ & $<0.001$ \\
\hline NHIS does not cover physical examination for my health care & $4.2(1.7)$ & $3.0(1.7)$ & $2.9(1.7)$ & $4.8(1.8)$ & $3.6(1.8)$ & $<0.001$ \\
\hline With NHIS, I have long waiting time at the facility & $2.9(1.8)$ & $3.7(1.4)$ & $3.9(1.4)$ & $4.9(1.8)$ & $4.1(1.2)$ & $<0.001$ \\
\hline $\begin{array}{l}\text { NHIS ensures that the vulnerable enjoys the same rights to } \\
\text { healthcare as other members in society }\end{array}$ & $4.3(1.6)$ & $4.8(1.6)$ & $4.6(1.8)$ & $5.5(1.8)$ & $4.7(1.9)$ & $<0.001$ \\
\hline Premium is too expensive considering my finances & $1.7(1.2)$ & $2.4(1.3)$ & $2.6(1.4)$ & $3.3(1.8)$ & $2.1(1.0)$ & $<0.001$ \\
\hline I am discriminated at the facility with NHIS & $1.7(1.1)$ & $2.0(1.2)$ & $2.0(1.2)$ & $2.8(1.9)$ & $1.6(7.5)$ & $<0.001$ \\
\hline
\end{tabular}

* People with disabilities, drug users, prisoners, and orphans; NHIS = National Health Insurance Scheme. \# Mean computed from response on a 7-point Likert scale: 1 = strongly disagree, $2=$ disagree, $3=$ somewhat disagree, $4=$ neutral, $5=$ somewhat agree, $6=$ agree, and $7=$ strongly agree.

NHIS card, whereas the sex workers were more likely to aess a private facility with their NHIS card (Table 4).

\subsection{Association between the Type of Vulnerable Group and} Health Service Utilization. Table 5 shows the results of the prevalence ratios (PR) and corresponding 95\% CI for the association between the type of vulnerable group and accessibility and affordability of healthcare, adjusted for sociodemographic and healthcare-related factors. In the crude models, pregnant women had lower PR of access to medications as compared to the elderly (PR, 95\% CI; 0.88,
0.80-0.98). The differences in healthcare access observed were however attenuated after adjustment for sociodemographic characteristics and healthcare-related factors. Having tertiary education, having more children, being exempted under the NHIS, and having a good relationship with health staff were associated with higher PR of access to medications. Being an active member of the NHIS was negatively associated with access to medications, whereas being exempted under the NHIS scheme and perception of health staff were positively associated. 
TABLE 4: Acceptability of health services under the NHIS.

\begin{tabular}{|c|c|c|c|c|c|c|c|}
\hline \multirow[b]{2}{*}{ Variables } & \multirow{2}{*}{$\begin{array}{c}\text { Total sample } \\
(\%)\end{array}$} & \multicolumn{5}{|c|}{ Vulnerable groups } & \multirow{2}{*}{$\begin{array}{c}P \\
\text { value }\end{array}$} \\
\hline & & $\begin{array}{l}\text { Elderly } \\
(\%)\end{array}$ & $\begin{array}{c}\text { Pregnant women } \\
(\%)\end{array}$ & $\begin{array}{l}\text { Female porters } \\
(\%)\end{array}$ & $\begin{array}{l}\text { Sex workers } \\
(\%)\end{array}$ & $\begin{array}{l}\text { Others* } \\
(\%)\end{array}$ & \\
\hline \multicolumn{8}{|l|}{ NHIS status } \\
\hline Insured & 97.7 & 99.2 & 96.3 & 94.2 & 95.9 & 100.0 & \multirow[t]{2}{*}{0.021} \\
\hline Uninsured & 2.3 & 0.8 & 3.7 & 5.8 & 4.1 & 0.0 & \\
\hline \multicolumn{8}{|l|}{ If status is active, do you always use it? } \\
\hline Yes & 95.7 & 96.0 & 89.5 & 93.6 & 87.1 & 94.0 & \multirow{2}{*}{0.035} \\
\hline No & 4.3 & 4.0 & 10.5 & 6.4 & 12.9 & dd 6.0 & \\
\hline $\begin{array}{l}\text { Ever been exempted from paying the } \\
\text { NHIS premium }\end{array}$ & 44.0 & 34.9 & 59.8 & 61.0 & 26.0 & 64.0 & $<0.001$ \\
\hline \multicolumn{8}{|l|}{ Source of payment for your NHIS } \\
\hline Self-payment & 59.1 & 71.8 & 37.8 & 34.2 & 77.3 & 28.2 & \multirow{4}{*}{$<0.001$} \\
\hline Dependent & 1.7 & 1.7 & 2.5 & 1.4 & 1.5 & 0.0 & \\
\hline Deduction from salary & 0.6 & 0.0 & 0.0 & 4.1 & 0.0 & 2.6 & \\
\hline Exemption benefit to payment & 38.5 & 26.5 & 59.7 & 60.3 & 21.2 & 69.2 & \\
\hline \multicolumn{8}{|c|}{ Pay money for services even with your NHIS card } \\
\hline Yes & 25.1 & 23.9 & 19.0 & 27.2 & 28.6 & 40.0 & \multirow{3}{*}{$<0.001$} \\
\hline No & 27.2 & 27.7 & 32.5 & 33.3 & 2.9 & 34.0 & \\
\hline Sometimes & 47.7 & 48.5 & 48.4 & 39.5 & 68.6 & 26.0 & \\
\hline \multicolumn{8}{|c|}{ Encountered any problem since you started using NHIS } \\
\hline Yes & 11.8 & 6.6 & 12.4 & 14.3 & 17.1 & 30.6 & \multirow{2}{*}{$<0.001$} \\
\hline No & 88.2 & 93.4 & 87.6 & 85.7 & 82.9 & 69.4 & \\
\hline \multicolumn{8}{|l|}{ Source of care accessed with your NHIS } \\
\hline Public & 92.9 & 98.5 & 92.0 & 86.4 & 76.1 & 91.5 & \multirow{2}{*}{$<0.001$} \\
\hline Private & 7.1 & 1.5 & 8.0 & 13.6 & 23.9 & 8.5 & \\
\hline
\end{tabular}

${ }^{*}$ People with disabilities, drug users, prisoners, and orphans; NHIS = National Health Insurance Scheme.

TABLE 5: Prevalence ratios and 95\% CI for the association between the type of vulnerability and healthcare utilization.

\begin{tabular}{|c|c|c|c|}
\hline \multirow{2}{*}{ Covariates } & \multicolumn{3}{|c|}{ Access to medications $\#$} \\
\hline & PR [95\% CI] & Model 1 PR [95\% CI] & Model 2 PR [95\% CI] \\
\hline \multicolumn{4}{|l|}{ Vulnerable groups } \\
\hline Elderly & 1.00 & 1.00 & 1.00 \\
\hline Pregnant women & $0.88[0.80,0.98]^{*}$ & $0.99[0.80,1.22]$ & $0.90[0.72,1.12]$ \\
\hline Head porters & $0.94[0.84,1.06]$ & $1.13[0.86,1.49]$ & $1.05[0.82,1.34]$ \\
\hline Sex workers & $0.99[0.90,1.10]$ & $1.22[0.94,1.57]$ & $1.09[0.84,1.42]$ \\
\hline Others & $0.90[0.77,1.05]$ & $1.28[0.80,2.04]$ & $1.17[0.75,1.83]$ \\
\hline \multicolumn{4}{|c|}{ Sociodemographic characteristics } \\
\hline Gender, female & & $1.08[0.93,1.26]$ & $1.08[0.95,1.23]$ \\
\hline Age & & $1.00[0.99,1.00]$ & $1.00[0.96,1.01]$ \\
\hline \multicolumn{4}{|l|}{ Level of education } \\
\hline None & & 1.00 & 1.00 \\
\hline Basic & & $0.96[0.87,1.06]$ & $1.06[0.96,1.18]$ \\
\hline Senior high school & & $0.86[0.73,1.01]$ & $0.92[0.78,1.09]$ \\
\hline Tertiary & & $1.18[1.05,1.31]^{* *}$ & $1.34[1.16,1.53]^{* * *}$ \\
\hline Unemployed & & $1.14[1.01,1.28]^{*}$ & $1.06[1.03,1.09]^{* * *}$ \\
\hline \multicolumn{4}{|l|}{ Marital status } \\
\hline Single & & 1.00 & 1.00 \\
\hline Married/cohabitation & & $0.89[0.75,1.05]$ & $0.96[0.82,1.13]$ \\
\hline Divorced/widow & & $0.98[0.82,1.15]$ & $1.08[0.94,1.24]$ \\
\hline Number of children & & $1.08[1.05,1.12]^{* * *}$ & $1.06[1.03,1.09]^{* * *}$ \\
\hline \multicolumn{4}{|l|}{ Religion } \\
\hline Christian & & 1.00 & 1.00 \\
\hline Muslim & & $0.94[0.79,1.05]$ & $1.06[0.90,1.25]$ \\
\hline
\end{tabular}


TABle 5: Continued.

\begin{tabular}{|c|c|c|c|}
\hline \multirow{2}{*}{ Covariates } & \multicolumn{3}{|c|}{ Access to medications $\#$} \\
\hline & PR [95\% CI] & Model 1 PR [95\% CI] & Model 2 PR [95\% CI] \\
\hline Others & & $0.99[0.84,1.16]$ & $0.80[0.67,0.96]^{*}$ \\
\hline \multicolumn{4}{|c|}{ Wealth quintiles } \\
\hline Low & & 1.00 & 1.00 \\
\hline Medium & & $1.02[0.93,1.22]$ & $1.03[0.94,1.13]$ \\
\hline High & & $0.88[0.79,0.96]^{* * *}$ & $0.86[0.77,0.95]^{* *}$ \\
\hline \multicolumn{4}{|c|}{ Healthcare-related factors } \\
\hline NHIS & & & $0.58[0.52,0.65]^{* * *}$ \\
\hline Exemption & & & $1.15[1.05,1.26]^{* *}$ \\
\hline
\end{tabular}

\section{Discussion}

The main finding of this study is the suboptimal utilization of healthcare among some vulnerable populations. Limited funding, poor attitude of service providers, and distance to health centers were important reasons for inability to access healthcare. Acceptability of service provision under the NHIS was low among the vulnerable groups. Less than half of the vulnerable groups had ever been exempted from the NHIS premium and most active members pay for services under the NHIS. The NHIS is unable to fully cater for the cost of healthcare for vulnerable groups due to the inability to identify the vulnerable populations and general financial challenges with the scheme.

In this study, although majority of the vulnerable populations could access healthcare, some disclosed that they had experienced some difficulties and were unable to access healthcare at any point in time during the previous 12 months. Limited funding, poor attitude of service providers, and distance to health centers were some reasons for their inability to access healthcare. Globally, PHC constitutes an integral part of countries' health system, mainly the first level of contact of individuals, families, and communities. It also brings healthcare as close as possible to where people live and work and constitutes the first element of continuing healthcare process [27]. Accessibility can however be observed from different points of view such as availability of services, transport costs to obtain service, or the distance or state of road to be travelled.

\subsection{Nondifferential Access to Healthcare among Vulnerable} People. This study found significant differences in the access to healthcare among vulnerable populations in the bivariate analysis, and these differences were no more significant in the multivariable analysis where possible confounders were controlled. This suggests that the differences in healthcare access among vulnerable groups could be explained by other factors including sociodemographic characteristics such as education, wealth, number of children, exemption from NHIS, and having a good relationship with health staff. The educated had higher access to healthcare among the various vulnerable populations. This corroborates many previous studies that have aessed this association in many settings. Education provides basic skills, including fundamental knowledge, ability to reason, ability to interact, and selfregulation of emotion, which are important aspects of health seeking [28]. The educated is thought to be more aware of their health or more likely to be wealthy and, therefore, could afford healthcare [29]. This suggests that an improvement in education and awareness about healthcare could improve healthcare access among vulnerable populations. Programmes that focus on closing gaps in educational outcomes between vulnerable, minority populations and the well-off and majority populations are needed to ensure health equity [28].

The relationship with healthcare staff has also been shown to influence the access to healthcare among vulnerable populations. In the Atwima Nwabiagya District in Ghana, a study among older people reported perceived respectful attitude of formal healthcare providers as barriers to healthcare utilization [30]. It is believed that the majority of healthcare workers are insensitive or lack training on how to handle and interact with vulnerable people including the elderly and the disabled [31, 32]. Training should be provided for health workers on how to appropriately provide care to the vulnerable people and this should be complemented with support systems for the health workers to be able to provide the needed care to vulnerable populations.

\subsection{Transportation Barriers and Access to Healthcare among} Vulnerable Populations. Transportation barriers are important nonfinancial barriers to healthcare access [33-36]. Barriers in transportation could result in rescheduled or missed appointments, delayed care, and even missed or delayed medication use, leading to poor disease management and poorer health outcomes [36]. In the model of relationship between transportation, healthcare access, and outcomes, Syed et al. [36] outlined the impact of transportation on access to healthcare and medical access and how that in turn relates with improved health outcomes and the prevention of chronic diseases (Supplementary Figure 2). Most of the respondents visited the health facility by means of a car. The means of transport to the source of healthcare also differed significantly among the vulnerable groups. A review of factors affecting the access to $\mathrm{PHC}$ services among persons with disabilities in rural settings, for instance, has reported on transportation challenges as a major barrier to healthcare access among the disabled [37]. 
A study among poor older people in the Atwima Nwabiagya District of Ghana, for instance, reported various transportation challenges to formal healthcare utilization among older people, including cost of transportation and poor transport systems [30]. Among older people with limited physical strength, walking for shorter distances for healthcare can even become an insurmountable problem. Thus, the opportunity to have a means of transportation becomes very important [30]. Atuoye et al. [38] also reported on the impact of lack of vehicular transport on access to maternal and child health in the Upper West region of Ghana, whereas Badu, Agyei-Baffour, and Opoku have also shown how transportation challenges influence access to healthcare among the disabled in the Kumasi Metropolis of Ghana.

\subsection{Acceptability of Health Services under the National Health} Insurance Scheme. NHIS coverage has increased healthcare utilization among older adults [39] and improved access to maternal and child health services, including antenatal care $[40,41]$ despite the challenges with inequalities. Individuals enrolled in the insurance scheme are reported to be significantly more likely to obtain prescriptions, visit clinics, and seek formal healthcare when sick [42]. However, some population subgroups especially the vulnerable are not able to access services under the NHIS [43].

About $88 \%$ of the vulnerable groups studied were current members of the NHIS. Majority of the vulnerable populations paid for their NHIS coverage, whereas only about $40 \%$ had been exempted from payment. The proportion of respondents who had ever been exempted was significantly higher among the female poters and pregnant women and lower among the sex workers. This could be the result of the inability of the exemption programme to adequately identify vulnerable groups who are deemed to benefit from the programme. As indicated by Kanchebe Derbile and van der Geest, NHIS exemptions in Ghana have failed to address the concerns of health equity as the poor has very little access to exemptions [44]. A study among 15 communities in the Central and Eastern Regions of Ghana also found the poor to have the lowest enrolment rate despite the presence of subsidy and exemptions for enrolment into the scheme [45]. The challenges with targeting services to the poor have also been reported for other health insurance schemes in other countries, including Rwanda and Ethiopia $[46,47]$. The exemption programme in Rwanda has however been more effective as a result of investment in a stratification process to systematically identify the poor to access all social programmes in the country. Countries like Tanzania and Kenya have no specific exemptions for the poor, but the people who are identified as poor are assisted to pay their healthcare bills through issuance of waivers [46].

The implementation of exemptions by the NHIS has been fraught with challenges, ranging from low level of awareness to difficulty in identifying the poor who needs to benefit from the scheme. Despite the implementation of exemptions in some facilities, it is revealed that the awareness of exemptions for other categories such as antenatal, under-fives, and the elderly is higher than for the poor $[44,48]$. The lack of awareness of the category of people and services that are covered for free has been cited as a barrier to enrolling in the NHIS [49]. Among those who are aware of the exemptions for the poor, some lack knowledge on the modalities for accessing it [44]. The inequities in knowledge of specific categories of exemptions are partly attributed to institutional factors and the nature of public education on exemptions [44] as well as higher demands for under-fives and antenatal exemptions, which place a heavy financial burden on the healthcare system, serving as a disincentive for further exemption education [44].

Other supply-related challenges included the difficulty for service providers to identify the poor due to lack of clarity for operationalization as a result of unclear guidelines, varied institutional interpretation of the policy, lack of documentation or comprehensive database systems on potential clients, and lack of adequate social workers [44]. Previous evidence suggests that, in some instances, healthcare providers reclassified bad debt as exemptions for the poor [44]. Despite being allowed by the guidelines to identify the poor, the mandate was vested in social workers affiliated to the Department of Social Welfare, who decide on one's status after social and economic assessments of the individual. A previous assessment however found none or at best one social worker (in case of a hospital) affiliated to most health facilities with responsibilities for exemptions [44]. The use of international definition of poverty as criteria for exemption for premium payment also leads to misclassifications as there are many unique variables that define the concept of poverty in Ghana [50-52].

Although most of the vulnerable populations studied used their NHIS card to access healthcare at the public facility, some still paid for services. The limited usability of the NHIS among vulnerable populations could be partly attributed to challenges encountered while using the NHIS card. As disclosed by participants in this study, the use of the NHIS card is associated with copayment issues, drug unavailability, rejection of the NHIS card occasionally, problems with renewal, expensive premium, and refusal of some facilities to accept NHIS. Respondents who had not renewed their NHIS subscription, for instance, cited lack of funds $(84.5 \%)$ and poor quality of services $(85.4 \%)$ as reasons for not renewing their subscription. To this end, the vulnerable groups believed that the PHC received under the NHIS is not enough to provide healthcare needs and does not cover all medical and other equipment expenses despite the perception that the NHIS is a pro-poor initiative and hence provides financial protection for the vulnerable. This corroborates a recent review of empirical and grey literature on the NHIS in Ghana and found emerging challenges of the NHIS such as administrative constraints, poor quality of healthcare to NHIS-insured clients, and limited revenue sources [17]. A previous study in Ghana also outlined poor service quality and lack of funds as important reasons for their inability to renew their health insurance policy [53]. Service provision under the NHIS should be improved to enhance subscription and to provide the needed service to vulnerable people. The NHIS should promote the policy by 
introducing more drugs and services to the already existing ones to help eradicate entirely out-of-pocket payment.

The economic benefit of the use of health insurance is to reduce the out-of-pocket payment for healthcare by providing financial risk protection and also reduce vulnerability and poverty $[54,55]$. This has however not been fully realized. Older people are, for instance, exempted from the NHIS premium although they still must pay the registration fee to access healthcare under the NHIS programme. Other groups, who cannot show a source of income and have no fixed residence (defined as the "core poor"), are also exempted from paying the NHIS premium [56]. Vulnerable populations are not able to afford the NHIS premium and are therefore unable to benefit from the scheme. It is previously reported that some head poters, for instance, cannot benefit from the NHIS scheme due to their inability to afford the NHIS premium [57]. This could be related to financial and operational challenges that threaten the sustainability of the scheme. For instance, evidence show the lack of funding for the NHIS, with cost incurred in funding exemption programmes such as free maternal health policy exceeding 4 times the seed grant provided by donors [50, 58, 59]. Other challenges include high rate of nonrenewal [50], low subscription rate (with $<40 \%$ adults being subscribed to the NHIS), payment default for service providers for the services provided for clients under the scheme [60], systemic corruption including issuance of false claims for reimbursement [50], cost escalation, possible political interference, inadequate technical capacity, inadequate monitoring mechanisms, broad benefits package and large exemption groups, inadequate client education, and limited community engagement [17].

Supply- and demand-side recommendations to improve the NHIS include sourcing for extra funding for the NHIS through oil revenue, and levies on large profitable companies and increasing value added tax (VAT) levy were proposed to promote financial sustainability of the NHIS $[17,61]$. Improving revenue collection, implementation of stringent monitoring mechanisms on health providers, and general policy reforms on the generous broad benefits package under the current NHIS could also help the scheme generate income and improve on its financial sustainability [17, 62]. There is also the need to improve the geographical accessibility of accredited health facilities and improve the material and human resource capacity to minimize workloads at the health facilities and the NHIA offices [63]. Previous review on challenges in the NHIS also suggested the need to decouple politics from the routine management activities of the NHIS as this stifles the progress and sustainability of the scheme [17].

4.4. Theoretical Implications. This study was based on previous conceptualizations of access, taking into account social and health dimensions of access within an equity perspective [20-23]. Finding from this study shows that the quality of healthcare accessed by vulnerable populations under the NHIS in Ghana is not optimal, and it is influenced by demand- and supply-related factors. Differences in access to healthcare among vulnerable populations are influenced by both sociodemographic factors such as education and health-related factors, including their relationship with health staff. Accessibility of healthcare depends to a large extent on their subscription to the NHIS scheme, which also relates to their ability to pay the premium or being exempted from it. Operational challenges with the scheme however hamper the capacity of the NHIA to effectively manage the exemption programme and to equitably identify the poor and vulnerable who are deemed for exemptions under the programme. Other challenges include the lack of clarity for operationalization of exemptions as a result of unclear guidelines and varied institutional interpretations of the policy.

4.5. Strengths and Limitations of the Study. This is the first study that explores differences in healthcare access among vulnerable populations using both quantitative and qualitative methods. By ensuring consistent measures and data collection across sites, it is believed that findings from this study are more generalizable and applicable to the study setting. However, although this study documents some important findings about the utilization of PHC by different vulnerable groups, the perceptions and views of health workers as well as health facility-related challenges were not explored. The study might also suffer from respondents and social desirability bias, and respondents might have the propensity to give more acceptable responses than what is more reflective of their thoughts about the NHIS and PHC or their experiences and challenges with access and utilization of healthcare [64]. The study also did not have a representative sample of all vulnerable groups in the population. There was limited sample from people with disabilities, drug users, prisoners, and orphans, and these were therefore grouped together as "other vulnerable groups". The multivariable analysis could not control all relevant factors that could influence the association between the type of vulnerability and access to healthcare.

\section{Conclusion}

In conclusion, there is suboptimal access and utilization of PHC among vulnerable populations in the Kumasi Metropolis. The differences in healthcare access among vulnerable groups were found to be partly explained by sociodemographic characteristics such as education, wealth, and number of children, exemption from NHIS, and having a good relationship with health staff. Transportation barriers and financial challenges were key factors that influenced access and utilization of PHC among vulnerable groups. The NHIS has not been able to fully alleviate financial challenges to healthcare access among vulnerable populations. The use of the NHIS card is associated with copayment issues, drug unavailability, rejection of the NHIS card occasionally, problems with renewal, expensive premium, and refusal of some facilities to accept NHIS. Bridging these gaps could go a long way to improve health access among vulnerable populations. Service provision under the NHIS should be 
improved to enhance subscription and to provide the needed service to vulnerable people. The NHIA should ensure that the exemption programmes are effectively implemented. This should include using appropriate measures to identify all vulnerable people who are deemed to benefit from the service. Further studies are needed to explore the perceptions and challenges of health workers on the provision of healthcare to vulnerable populations. Further stakeholder analysis on the NHIA is also needed to better understand the challenges with the implementation of the NHIS as well as the rolling out the exemptions for vulnerable populations.

\section{Data Availability}

The datasets used and/or analyzed during the current study are available from the corresponding author on reasonable request.

\section{Ethical Approval}

The Committee for Human Research Publication and Ethics at Kwame Nkrumah University of Science and Technology (KNUST)/Komfo Anokye Teaching Hospital (KATH) reviewed and cleared the study protocols prior to the implementation of the methods.

\section{Consent}

Assurance of strict privacy will motivate prospective study participants. Informed consent, confidentiality, and data protection are the significant issues included. A written informed consent was explained to participants who consented to the study prior to their enrolment.

\section{Conflicts of Interest}

The authors declare no conflicts of interest.

\section{Authors' Contributions}

GA-H and PA-B conceptualized the study. GA-H and PA-B collected the data. DB conducted the statistical analyses and together with GA-H wrote the first draft of the manuscript. All authors critically reviewed and approved the manuscript prior to publication.

\section{Acknowledgments}

The authors acknowledge the support of the research assistants, chief, Queen mother, and the leadership of the vulnerable groups in Kumasi in reaching out to the study population.

\section{Supplementary Materials}

Supplementary Table 1 describes the operational definitions of each access dimension. For example, on the demand side, ability to perceive is, for instance, defined as "the ability of people to identify their needs of healthcare" whereas the corresponding supply dimension, approachability refers to "the fact that people in need of healthcare can identify that some form of services exists, can be reached, and have an impact on their health". Supplementary Table 2 shows the description of the study variables in this study including their contextual definition. This includes the contextual definition for the sociodemographic characteristics and healthcare-related factors. Supplementary Figure 1 shows the dimensions of healthcare accessibility as proposed by Levesque et al. [20]. The dimensions are arranged in pairs, with each access and demand-side abilities mirroring each other. The dimensions of accessibility are approachability, acceptability, availability accommodation, affordability, and appropriateness; and the corresponding abilities of patients and populations to access healthcare were ability to perceive, ability to seek, ability to reach, ability to pay, and ability to engage. Supplementary Figure 2 illustrates the relationship between transportation, healthcare access, and outcomes as proposed by Syed et al. [36]. The model outlined the impact of transportation on healthcare and medication access as well as how that influences health outcomes and the prevention of chronic diseases. (Supplementary Materials)

\section{References}

[1] World Health Organization, Sustainable Development Goals Knowledge Platform, WHO, Geneva, Switzerland, 2021.

[2] J. Goudge, L. Gilson, S. Russell, T. Gumede, and A. Mills, "Affordability, availability and acceptability barriers to health care for the chronically ill: longitudinal case studies from South Africa," BMC Health Services Research, vol. 9, no. 1, p. 75, 2009.

[3] D. McIntyre, M. Thiede, and S. Birch, "Access as a policyrelevant concept in low- and middle-income countries," Health Economics, Policy and Law, vol. 4, no. 2, pp. 179-193, 2009.

[4] M. Gulliford, J. Figueroa-Munoz, M. Morgan et al., "What does "access to health care" mean?" Journal of Health Services Research \& Policy, vol. 7, no. 3, pp. 186-188, 2002.

[5] J. A. Ford, G. Wong, A. P. Jones, and N. Steel, "Access to primary care for socioeconomically disadvantaged older people in rural areas: a realist review," BMJ Open, vol. 6, no. 5, Article ID e010652, 2016.

[6] Mujib-ur-Rehman, N. Khan, and M. Abbas, "Availability and utilization of primary health care services in the rural areas of district peshawar - a case study," Sarhad Journal of Agriculture, vol. 23, no. 4, 2007.

[7] M. Dixon Woods, D. Kirk, S. Agarwal, E. Annandale, T. Arthur, and J. Harvey, "Vulnerable groups and access to health care: a critical interpretive review," Report for the National Co-ordinating. Centre for NHS Service Delivery and Childbirth (NCCSDO), vol. 483, 2005.

[8] African Child Policy Forum, "The african report on children with disabilities," 2014.

[9] A. G. Farran, "African healthcare "failing to reach vulnerable groups," 2021, https://medicalxpress.com/news/2021-04african-healthcare-vulnerable-groups.html.

[10] European Centre for Disease Prevention and Control, Interventions in Vulnerable Groups Are the Key to Eliminating Tuberculosis in Europe, ECDC Policy Brief, Solna, Sweden, 2016.

[11] G. Siân, D. Katy, and F. Evridiki, "A qualitative study into the perceived barriers of accessing healthcare among a vulnerable 
population involved with a community centre in Romania," International Journal for Equity in Health, vol. 17, no. 1, pp. 1-13, 2018.

[12] M. Seid, E. J. Sobo, L. R. Gelhard, and J. W. Varni, "Parents' reports of barriers to care for children with special health care needs: development and validation of the barriers to care questionnaire," Ambulatory Pediatrics, vol. 4, no. 4, pp. 323-331, 2004.

[13] F. O. Baah, A. M. Teitelman, and B. Riegel, "Marginalization: conceptualizing patient vulnerabilities in the framework of social determinants of health-an integrative review," Nursing Inquiry, vol. 26, no. 1, Article ID e12268, 2019.

[14] K. J. Kerber, J. E. de Graft-Johnson, Z. A. Bhutta, P. Okong, A. Starrs, and J. E. Lawn, "Continuum of care for maternal, newborn, and child health: from slogan to service delivery," The Lancet, vol. 370, no. 9595, pp. 1358-1369, 2007.

[15] A. Mills, J. E. Ataguba, J. Akazili, J. Borghi, B. Garshong, and S. Makawia, "Equity in financing and use of health care in Ghana, South Africa, and Tanzania: implications for paths to universal coverage," Lancet, vol. 14, no. 9837, pp. 126-133, 2012.

[16] M. Kolbe Domapielle, "Health insurance and access to health care services in developing countries," Journal of Government and Politics, vol. 5, no. 1, pp. 80-91, 2014.

[17] R. K. Alhassan, E. Nketiah-Amponsah, and D. K. Arhinful, “A review of the national health insurance scheme in Ghana: what are the sustainability threats and prospects?" PLoS One, vol. 11, no. 11, Article ID e0165151, 2016.

[18] N. J. Blanchet, G. Fink, and I. Osei-Akoto, "The effect of Ghana's National Health Insurance Scheme on health care utilisation," Ghana Medical Journal, vol. 46, no. 2, pp. 76-84, 2012.

[19] S. Witter and B. Garshong, "Something old or something new? Social health insurance in Ghana," BMC International Health and Human Rights, vol. 9, 2009.

[20] J. F. Levesque, M. F. Harris, and G. Russell, "Patient-centred access to health care: conceptualising access at the interface of health systems and populations," International Journal for Equity in Health, vol. 18, 2013.

[21] J. Frenk, "Concept and measurement of accessibility," Salud Publica Mex, vol. 27, no. 5, pp. 438-453, 1985, http://www. ncbi.nlm.nih.gov/pubmed/4081889.

[22] S. Artiga and E. Hinton, Beyond Health Care: The Role of Social Determinants in Promoting Health and Health Equity, Kaiser Family Foundation Kaiser Communications Medicaid Uninsured, San Francisco, CA, USA, 2018, http://files.kff.org/ attachment/issue-brief-beyond-health-care.

[23] P. A. Braveman, "Monitoring equity in health and healthcare: a conceptual framework," Journal of Health, Population and Nutrition, vol. 21, no. 3, pp. 181-192, 2003.

[24] Ghana Statistical Service. 2010, Population and Housing Census: District Analytical Report, Kumasi Metropolitan, Accra, Ghana, 2014.

[25] B. R. Kirkwood and J. A. C. Sterne, "Essential medical statistics," Medical Statistics, vol. 11, 2003.

[26] G. Zou, "A modified Poisson regression approach to prospective studies with binary data," American Journal of Epidemiology, vol. 159, no. 7, pp. 702-706, 2004.

[27] A. M. Adebayo and M. C. Asuzu, "Utilisation of a communitybased health facility in a low-income urban community in Ibadan, Nigeria," African Journal of Primary Health Care \& Family Medicine, vol. 7, no. 1, pp. 1-8, 2015.
[28] R. A. Hahn and B. I. Truman, "Education improves public health and promotes health equity," International Journal of Health Services, vol. 45, no. 4, pp. 657-678, 2015.

[29] D. P. Baker, J. Leon, E. G. Smith Greenaway, J. Collins, and M. Movit, "The education effect on population health: a reassessment," Population and Development Review, vol. 37, no. 2, pp. 307-332, 2011.

[30] W. Agyemang-Duah, C. Peprah, and P. Peprah, "Barriers to formal healthcare utilisation among poor older people under the livelihood empowerment against poverty programme in the Atwima Nwabiagya District of Ghana," BMC Public Health, vol. 19, no. 1, p. 1185, 2019.

[31] J. K. Ganle, E. Otupiri, B. Obeng, A. K. Edusie, A. Ankomah, and R. Adanu, "Challenges women with disability face in accessing and using maternal healthcare services in Ghana: a qualitative study," PLoS One, vol. 11, no. 6, Article ID e0158361, 2016.

[32] M. Mulumba, J. Nantaba, C. E. Brolan, A. L. Ruano, K. Brooker, and R. Hammonds, "Perceptions and experiences of access to public healthcare by people with disabilities and older people in Uganda," International Journal for Equity in Health, vol. 13, no. 1, p. 76, 2014.

[33] C. Buzza, S. S. Ono, C. Turvey, S. Wittrock, M. Noble, and G. Reddy, "Distance is relative: unpacking a principal barrier in rural healthcare," Journal of General Internal Medicine, vol. 26, no. 2, pp. 648-654, 2011.

[34] S. M. Ahmed, J. P. Lemkau, N. Nealeigh, and B. Mann, "Barriers to healthcare access in a non-elderly urban poor American population," Health of Social Care in the Community, vol. 9, no. 6, pp. 445-453, 2001.

[35] A. Kamimura, S. Panahi, Z. Ahmmad, M. Pye, and J. Ashby, "Transportation and other nonfinancial barriers among uninsured primary care patients," Health Services Research and Managerial Epidemiology, vol. 5, 2018.

[36] S. T. Syed, B. S. Gerber, and L. K. Sharp, "Traveling towards disease: transportation barriers to health care access," Journal of Community Health, vol. 38, no. 5, pp. 976-993, 2013.

[37] E. Dassah, H. Aldersey, M. A. McColl, and C. Davison, "Factors affecting access to primary health care services for persons with disabilities in rural areas: a "best-fit" framework synthesis," Global Health Research and Policy, vol. 3, no. 1, p. 36, 2018.

[38] K. N. Atuoye, J. Dixon, A. Rishworth, S. Z. Galaa, S. A. Boamah, and I. Luginaah, "Can she make it? Transportation barriers to accessing maternal and child health care services in rural Ghana," BMC Health Services Research, vol. 15, no. 1, p. 333, 2015.

[39] N. Van Der Wielen, A. A. Channon, and J. Falkingham, "Evidence from the national health insurance scheme in Ghana," BMJ Global Health, vol. 3, p. 590, 2018.

[40] S. Bosomprah, P. L. Ragno, C. Gros, and H. Banskota, "Health insurance and maternal, newborn services utilisation and under-five mortality," Archives of public health = Archives belges de sante publique, vol. 73, no. 1, p. 51, 2015.

[41] E. K. Ameyaw, B. O. Ahinkorah, L. Baatiema, and A.-A. Seidu, "Is the National Health Insurance Scheme helping pregnant women in accessing health services? analysis of the 2014 Ghana demographic and Health survey," BMC Pregnancy and Childbirth, vol. 21, no. 1, pp. 1-8, 2021.

[42] N. J. Blanchet, G. Fink, and I. Osei-Akoto, "The effect of Ghana's National Health Insurance Scheme on health care utilisation," Ghana Medical Journal, vol. 46, no. 2, pp. 76-84, 2012. 
[43] A. De Groot, L. Van De Munt, D. Boateng et al., "Equity in maternal health outcomes in a middle-income urban setting: a cohort study," Reproductive Health, vol. 16, no. 1, p. 84, 2019.

[44] E. Kanchebe Derbile and S. Van Der Geest, "Repackaging exemptions under National Health Insurance in Ghana: how can access to care for the poor be improved?" Health Policy and Planning, vol. 28, no. 6, pp. 586-595, 2013.

[45] A. M. Kotoh and S. Van Der Geest, "Why are the poor less covered in Ghana's national health insurance? a critical analysis of policy and practice," International Journal for Equity in Health, vol. 15, no. 1, 2016.

[46] A. P. Fenny, R. Yates, and R. Thompson, "Social health insurance schemes in Africa leave out the poor," International Health, vol. 10, no. 1, pp. 1-3, 2018.

[47] E. Spaan and J. Mathijssen, The Impact of Health Insurance in Africa and Asia: A Systematic Review, SciELO Public Health, São Paulo, Brazil, 2012, https://www.scielosp.org/article/ bwho/2012.v90n9/685-692/pt/.

[48] D. Arhinful, Review of Exemption Policy: A Report on the Annual Health Sector Review 2005, Ministry of Health, Accra, Ghana, 2005.

[49] K. Singh, I. Osei-Akoto, F. Otchere et al., "Ghana's National Health insurance scheme and maternal and child health: a mixed methods study," BMC Health Services Research, vol. 15, no. 1, p. 108, 2015.

[50] C. D. Christmals and K. Aidam, "Implementation of the national health insurance scheme (NHIS) in Ghana: lessons for South Africa and low- and middle-income countries," Risk Management and Healthcare Policy, vol. 13, pp. 1879-1904, 2020.

[51] A. P. Fenny, U. Enemark, F. A. Asante, and K. S. Hansen, "Patient satisfaction with primary health care - a comparison between the insured and non-insured under the National Health Insurance Policy in Ghana," Global Journal of Health Science, vol. 6, no. 4, pp. 9-21, 2014.

[52] G. C. Aryeetey, C. Jehu-Appiah, A. M Kotoh et al., "Community concepts of poverty: an application to premium exemptions in Ghana's National Health Insurance Scheme," Globalization and Health, vol. 9, no. 1, p. 12, 2013.

[53] D. Boateng and D. Awunyor-Vitor, "Health insurance in Ghana: evaluation of policy holders' perceptions and factors influencing policy renewal in the Volta region," International Journal for Equity in Health, vol. 12, no. 1, p. 50, 2013.

[54] G. Carrin, M.-P. Waelkens, and B. Criel, "Community-based health insurance in developing countries: a study of its contribution to the performance of health financing systems," Tropical Medicine and International Health, vol. 10, no. 8, pp. 799-811, 2005.

[55] E. W. Kanmiki, K. Id, J. F. PhillipsBawah et al., "Out-of-pocket payment for primary healthcare in the era of national health insurance: evidence from northern Ghana," Plos One, vol. 14, no. 8, Article ID e0221146, 2019.

[56] National Health Insurance Authority, National Health Insurance Scheme, National Health Insurance Authority, Accra, Ghana, 2017, http://www.nhis.gov.gh/nhia.aspx.

[57] S. H. Nyarko and A. M. Tahiru, "Harsh working conditions and poor eating habits: health-related concerns of female head porters (Kayayei) in the Mallam Atta Market, Accra, Ghana," BioMed Research International, vol. 2018, pp. 1-7, 2018.

[58] A. Addae-Korankye and A. Addae-Korankye, "Challenges of financing health care in Ghana: the case of national health insurance scheme (NHIS)," International Journal of Asian Social Science, vol. 3, no. 2, pp. 511-522, 2013, https:// econpapers.repec.org/repec:asi:ijoass.
[59] E. Ankrah Odame, P. Akweongo, B. Yankah, F. Asenso-Boadi, and I. Agyepong, "Sustainability of recurrent expenditure on public social welfare programmes: expenditure analysis of the free maternal care programme of the Ghana National Health Insurance Scheme," Health Policy and Planning, vol. 29, no. 3, pp. 271-279, 2014.

[60] J. K. Awoonor-Williams, P. Tindana, P. A. Dalinjong, H. Nartey, and J. Akazili, "Does the operations of the national health insurance scheme (NHIS) in Ghana align with the goals of primary health care? perspectives of key stakeholders in northern Ghana," BMC International Health and Human Rights, vol. 16, pp. 1-11, 2016.

[61] G. A. Abiiro and D. McIntyre, "Universal financial protection through National Health Insurance: a stakeholder analysis of the proposed one-time premium payment policy in Ghana," Health Policy and Planning, vol. 28, no. 3, pp. 263-278, 2013.

[62] D. Adei, V. O. Kwadwo, and S. Diko, "An assessment of the kwabre district mutual health insurance scheme in Ghana," Current Research in Social Sciences, vol. 4, no. 5, pp. 372-382, 2012.

[63] P. A. Dalinjong and A. S. Laar, "The national health insurance scheme: perceptions and experiences of health care providers and clients in two districts of Ghana," Health Economics Review, vol. 2, no. 1, p. 13, 2012.

[64] P. Grimm, "Social desirability bias," in Wiley International Encyclopedia of Marketing, John Wiley \& Sons, Hoboken, NJ, USA, 2010. 